\title{
The impact of stress and social support on the mental health of individuals with intellectual disabilities
}

\author{
Yona Lunsky, $\mathrm{PhD}$ ( $^{(1)}$
}

\begin{abstract}
Lunsky Y.
The impact of stress and social support on the mental health of individuals with intellectual disabilities. Salud Publica Mex 2008;50 suppl 2:SI5I-SI 53.
\end{abstract}

\begin{abstract}
People with intellectual disabilities (ID) are at increased risk for mental health problems than the general population. The reasons for this are both biological and social. Current treatment for mental health problems tends to be reactive in nature with less emphasis on how mental health problems can be prevented.A better understanding of the social contributors to mental health in individuals with ID should lead to the prevention of mental health problems in this particularly vulnerable population. Two promising areas of research when thinking about mental health promotion and ID are stress and social support, which are reviewed here.
\end{abstract}

Key words: social support; stress; intellectual disability

\section{Lunsky Y.}

Efectos del estrés y del apoyo social sobre la salud mental de individuos con discapacidad intelectual.

Salud Publica Mex 2008;50 supl 2:SI5I-SI53.

\section{Resumen}

Las personas con discapacidad intelectual (DI) están más expuestas a sufrir problemas de salud mental que la población general. Las razones son tanto biológicas como sociales. El tratamiento actual para los problemas de salud mental tiende a ser reactivo por naturaleza, poniendo menor énfasis en la prevención. Una mejor comprensión de los contribuyentes sociales en la salud mental de los individuos con DI debería llevar a la prevención de problemas de salud mental en esta población particularmente vulnerable. Dos áreas de investigación promisorias cuando se piensa en promoción de la salud mental y DI son el estrés y el apoyo social, que aquí se revisan.

Palabras clave: apoyo social; estrés; discapacidad intelectual

\section{Stress}

One of the major contributors to mental health difficulties in the general population is the experience of stress. ${ }^{1}$ Individuals can feel stressed because of minor or daily hassles as well as in response to major life events such as the death of a parent, illness, or change in residence. We experience stress when we perceive an event as overly challenging and beyond our ability to cope. ${ }^{2}$ Individuals with ID are more vulnerable to stress than the general population because of their prior negative coping experiences, limited environmental supports, and a low belief in their own abilities; however, few studies on stress include this marginalized group. ${ }^{3}$

A handful of research studies from the $\mathrm{US}^{4}{ }^{4} \mathrm{Canada}^{3}$ and Australia ${ }^{5}$ have reported that individuals with ID experience some forms of stress similar to the general population but other forms of stress more frequently.

(I) University of Toronto, Centre for Addiction and Mental Health, Canada. 
The most common forms of stress reported in these studies include: hearing people argue, death or serious illness of someone close, constantly being interrupted, and not being quick enough. Interestingly, interpersonal stress seems to be most common. This may be because people with ID typically have limited control over who they are with and have limited ability to escape or end negative social interactions. ${ }^{6}$

In a recent Canadian study on stress experienced by adults with $\mathrm{ID}^{3}$ caregivers were asked to rate the stress experienced by those they care for, in parallel to self-reported stress. This study found that caregivers were not always aware of perceived stressors in those that they cared for, and that this lack of awareness was more evident in paid versus unpaid (family) caregivers. Caregivers focused more on inadequacies or coping deficits because of the person's disability than did the people with the disabilities themselves. Authors concluded that while it is important to learn about stress from caregivers, they may not always be aware of issues relevant to people with disabilities, and so it is important to assess stress from the two perspectives when possible. ${ }^{7}$

\section{Life events}

Individuals with ID experience the same stressful major life events as the general population, with some events being more frequent such as change in residence or loss of key support person (due to unavoidable changes in caregivers over time). Several studies have reported that significant life events are major triggers of emotional or behavioural crises in the ID population, ${ }^{8-10}$ and can result in inpatient hospital admissions, ${ }^{11}$ depression/ suicidality ${ }^{12}$ or problem behaviour. ${ }^{13}$ Crisis often follows the death of a parent, particularly when no plans are in place for the care of the person with the disability, or following other kinds of trauma such as abuse or serious injury. Because the concept of time is impaired for many people with ID, the crisis may occur some time after the life event. Clinicians need to remember that the impact of the event can still be major, even years after its occurrence.

\section{Implications}

More research is needed on the impact of stress in the lives of people with intellectual disabilities in Latin American countries. It may be that these individuals are exposed to different stressors than have been reported here. As well, they may have more or fewer resources available to help them cope with their stress than those with ID in other countries.
To improve the mental health of individuals with ID in all parts of the world, we have to pay attention to the impact that stress can have on their daily lives. When possible, we can work toward reducing stressful experiences through planning for major life events (e.g., death of parent), and responding when such life events occur with counseling or other supports. In addition, we can work toward teaching individuals with ID to better cope with experiences that are difficult for them. Such training would include teaching them to recognize that they are feeling stressed, and teaching them to solve problems in order to escape the stressful situation, or to ask for help from others. We can also do more work with caregivers of individuals with ID, teaching them to recognize stress and support those under their care when faced with stress. It is equally important to address the stress frequently experienced by the caregivers because their stress impacts not only their ability to function but also the stress experienced by the person under their care.

\section{Social support}

Social support can be defined as the interpersonal transactions or exchanges of resources between at least two people perceived by the provider or recipient to be intended to enhance the well-being of the recipient. ${ }^{14}$ It has long been recognized that having social support is a buffer to mental and physical illness in the general population. Social support is also important for people with intellectual disabilities and their families. Interestingly, more research attention has been given to the impact of social support on parents of those with intellectual disabilities than to people with disabilities themselves. Clearly, caregivers of people with ID require support from loved ones and practical support from people outside of the home in order to function competently. But it is just as important for those that they care for to have support from family, friends, and professionals.

Individuals with ID are significantly more likely to receive less emotional support from others than individuals without disabilities. ${ }^{15}$ Without support, individuals with ID can feel lonely and depressed. One cause of loneliness comes from the fact that individuals with ID receive the majority of their support from paid sources. ${ }^{16}$ Such relationships are not reciprocal in nature. The person with the disability cannot benefit from being a provider of support to someone else. Over time, one's reliance on paid support reduces one's ability to develop reciprocal relationships with others, making it less likely that unpaid supports will be found in the future. Also, these relationships can be temporary. The loss of a paid 
caregiver can be a cause of depression and even crisis in the life of someone with a disability who has very few people in his or her life.

When conducting research on social support in the ID population, it is important to think about how social support is measured. Researchers often turn to caregivers because of communication deficits of those with ID. The problem with this is that informant ratings of social support do not necessarily correspond to the perspective of those with disabilities. ${ }^{17}$ Research in the general population has found that it is one's perceptions of social support that buffer a person from becoming depressed, for example. Thus, if the person with the disability thinks he has social support, even if a caregiver does not, he or she may be buffered from becoming depressed to some extent. In one research study on perceived social support, we found that adults with ID tended to have "rose coloured glasses." They rated social interaction vignettes as more supportive than they actually were and these rosy ratings corresponded to their own perceptions of support, which they rated as high. The individuals who could more accurately rate the negative social interactions also reported lower levels of support for themselves. ${ }^{18}$

Social support researchers generally have thought of social support as an individual variable. But recent research in the geriatric population ${ }^{19}$ and in persons with $\mathrm{ID}^{20}$ has highlighted that social support can also be measured at the community level. Some people with ID report that they receive their social support from formal groups such as their bowling league, their roommates, or their church group. Other people with ID report that they get their social support from a particular place, such as a restaurant that they visit frequently, "church" or their workplace. The advantage of receiving community level support is that even if one person leaves the work or the church, the support is still there. This may be of particular importance for people who have problems remembering individual names, or developing personal relationships.

\section{Implications}

Thus, recent research on social support points to a few areas for intervention/mental health promotion for individuals with ID in Latin American countries. We need to invest in helping them to develop positive social relationships with unpaid individuals that are reciprocal in nature. We also need to encourage, particularly for those people lacking in individual supports, places of belonging or group support. Individuals with ID need to feel a part of a community and know there is some place where they can go to feel accepted and have healthy interactions with others. When researching social sup- port, we need to pay attention to the perspective of the person with the disability, and not just his or her caregiver. This may require creative methods of measuring social support, such as making a social support map, or using pictures, or even spending time with the person in places important to him or her.

\section{References}

I. O'Leary A. Stress, emotion and human immune function. Psychol Bull 1990; 108(3): 363-382.

2. Lazarus RS, Folkman S. Stress, appraisal, and coping. New York: Springer; 1984.

3. Lunsky Y, Bramston P. A premilinary study of perceived stress in adults with intellectual disabilities according to self-report and informant ratings. J Intellect Dev Disabil 2006;3I(I):20-27.

4. Hartley SL, MacLean WE. Perceptions of stress and coping strategies among adults with mild mental retardation: Insight into psychological distress. Am J Ment Retard 2005.

5. Bramston P, Fogarty G, Cummins RA. The nature of stressors reported by people with an intellectual disability. Journal of Applied Research in Intellectual Disabilities 1999; 12:1-10.

6. Lunsky Y, Benson B. The association between perceived social support and strain and positive and negative outcome for adults with mild intellectual disabilities. J Intellect Disabil Res 2001;45:106-II4. 7. Cummins RA. Proxy responding for subjective well-being:A review. Int Rev Res Ment Retard 2002;25:183-207.

8. Ghaziuddin M. Behavioural disorder in the mentally handicapped:The role of life events. Br J Psychiatry 1988; I52:683-686

9. Hatton C, Emerson E. The relationship between life events and psychopathology amongst children with intellectual disabilities. Journal of Applied Research in Intellectual Disabilities 2004; 17(2):109-1 17. 10. Lunsky Y. Depressive symptoms in intellectual disability: Does gender play a role? J Intellect Disabil Res 2003;47:417-427.

II. Stack LS, Haldipur CV,Thompson M. Stressful life events and psychiatric hospitalisation of mentally retarded patients. Am J Psychiatry 1987; 144:661-663.

12. Lunsky Y. Suicidality in a clinical and community sample of adults with mental retardation. Res Dev Disabil 2004;25:23I-243.

13. Esbensen A, Benson B.A prospective analysis of life events, problem behaviour and depression in adults with intellectual disabilities.J Intellect Disabil Res 2006;50:248-258.

14. Shumaker, SA, Brownell A. Toward a theory of social support: Closing conceptual gaps.J Soc Issues 1984;40: I I-36.

15. Havercamp SM, Scandlin D, Roth M. Health disparities among adults with developmental disabilities, adults with other disabilities, and adults not reporting disability in North Carolina. Public Health Rep 2002; 1 19:418-426.

16. Amado AN. Working on friendships. In: A. Amado, ed. Friendships and community connections between people with and without developmental disabilities. Baltimore: Paul H. Brookes Publishing, 1993;279-298.

17. Lunsky Y, Benson B. Reliability of ratings of consumers with mental retardation and their staff on multiple measures of social support.Am J Ment Retard 1997;102(3):280-284.

18. Lunsky Y, Benson B. Perceived social support and adults with mental retardation:A social-cognitive model. Cognit Ther Res 2001;25:77-90. 19. Felton B, Berry C. Groups as social network members: Overlooked sources of social support. Am J Community Psychol 1992;20:253-26I. 20. Lunsky Y, Neely L. Extra-individual sources of social support as described by adults with mild intellectual disabilities. Ment Retard 2002;40(4):269-277. 